\title{
O CINEMA EM GILLES DELEUZE: APONTAMENTOS SOBRE A IMAGEM- MOVIMENTO
}

\begin{abstract}
ANA LUÍSA COUTINHO FIALHO ${ }^{1}$
Resumo: Em Cinema 1 - A Imagem-Movimento (1983), Deleuze constrói conceitos que tratam dos elementos fundamentais de sua filosofia a respeito do cinema, tendo como ponto de partida a análise bergsoniana do movimento, em A Evolução Criadora (1907), e da imagem, em Matéria e Memória (1896) . Bergson, que conviveu com o cinema em seus primórdios (final do séc. XIX e início do séc. XX), faz menção a ele com uma concepção muito avessa àquela que a filosofia deleuziana viria a ter - apesar disso, sua crítica à maneira pela qual construímos nossa noção de movimento acaba conectando-se diretamente ao cinema pós-montagem, fertilizando um solo riquíssimo de análises filosóficas acerca do cinema, que Deleuze aproveitou para a elaboração de suas obras sobre o tema. O objetivo desse artigo é fortalecer a ponte entre a metafísica bergsoniana e a filosofia do cinema de Deleuze no sentido de entender a maneira particular pela qual Deleuze apropria-se de conceitos metafísicos de Bergson. Para isso, utilizamos análise estrutural dos textos mencionados, comparando-os. No final desse processo pudemos observar as relaçôes de sentido entre conceitos bergsonianos e os planos cinematográficos analisados por Deleuze.
\end{abstract}

Palavras-chave: Cinema; Deleuze; Bergson; Imagem-movimento.

São muitas as pontes passíveis de serem construídas entre o terreno artístico e o filosófico. Neste trabalho temos a intenção de explicitar a riqueza de detalhes da construção filosófica deleuziana acerca do cinema e a maneira pela qual ele utiliza, brilhantemente, a metafísica de Henri Bergson como matéria-prima para seus conceitos referentes à sétima arte.

Sem dúvidas, Bergson teria dificuldades de imaginar que sua filosofia poderia servir de fertilizante para uma obra que trata, justamente, de um fenômeno que ele não viu em

1 Bacharela em Filosofia pela Universidade Federal do ABC.

analu.coutinhof@gmail.com 
toda a sua potencialidade: o cinema. Quando faleceu, em 1941, tal arte estava "engatinhando": se utilizava da câmera parada e não contava fortemente com o recurso da montagem.

Reconhecemos que houve, tanto na metafísica bergsoniana quanto na filosofia do cinema deleuziana, uma grande genialidade: Bergson foi genial pois, ao descrever em sua metafísica a natureza das "imagens” no primeiro capítulo de Matéria e Memória (1896), e do movimento, em A Evolução Criadora (1907), ele prevê uma chave específica de leitura da natureza da realidade que os cineastas também adotarão, utilizando-se de outra espécie de ferramenta, isto é, a arte. Já Deleuze foi brilhante ao olhar com tanta sensibilidade para o cinema de seu tempo e para a filosofia de seu conterrâneo, realizando um eloquente processo de criação de conceitos sobre o cinema, sendo um dos conceitos centrais, aquele que nomeia o presente trabalho: a imagem-movimento.

Para Deleuze, o cinema, assim como as outras artes, a literatura e a filosofia, é um processo de criação - dessa maneira, o cinema é uma forma de exercer o pensamento de forma construtiva, criativa. Por isso, cineastas são pensadores que pensam não através de conceitos, mas de imagens.

Em Cinema 1: A Imagem-Movimento, obra que abordaremos nesse trabalho, Deleuze realiza dois comentários a Bergson: no primeiro, evoca as teses sobre o movimento presentes em $A$ Evolução Criadora, fundamentais para entendermos o conceito de imagem-movimento. Já no segundo comentário a Bergson, Deleuze trata das variaçóes da imagem-movimento: a imagem-ação, imagem-percepção e imagem-afecção.

\section{AS TRÊS TESES ACERCA DO MOVIMENTO - O PRIMEIRO COMENTÁ- RIO A BERGSON REALIZADO POR DELEUZE}

Na perspectiva deleuziana, o cineasta é, além de artista, um pensador - de modo diferente ao filósofo, que utiliza conceitos como ferramenta, o cineasta usa seus próprios instrumentos: imagem-movimento e imagem-tempo. Conceitos filosóficos seminais para Gilles Deleuze (1925 - 1995), que se referem aos "blocos" de movimento/duração produzidos pelo cineasta, como Deleuze cita em "O ato de criação", sua conferência dirigida para cineastas. Tais conceitos são tão seminais que, respectivamente, nomeiam os dois volumes da obra desse filósofo voltada à sétima arte.

Para compreendermos o conceito de "imagem-movimento" é fundamental compreender o conceito de "duração" de Bergson, ou seja, conceito de "tempo real". O que vale a 
pena chamar a atenção aqui a respeito desse conceito é a tentativa de "imaginar" o intangível. Nossa faculdade principal, a inteligência, volta-se à observação das semelhanças entre as coisas, das regularidades do real. Neste sentido, o que medimos com o relógio, que Bergson chama de “tempo espacializado" é uma tentativa de medição do tempo, mas, como aparece em sua obra, Bergson trata essa medição como uma medição do espaço.

O tempo real, que se refere à duração, é o tempo da consciência, qualitativo, que não pode ser medido e nem calculado, como observamos na primeira parte da introdução de O Pensamento e o Movente. (BERGSON, 1974) É nessa direção que Deleuze caminha quando aborda a "imagem-movimento" como blocos de duração, blocos de imagens-movimento ou, em outras palavras, blocos de um "todo" que muda continuamente. É esse o tipo de linguagem utilizada pelo cineasta para pensar.

$\mathrm{Na}$ "coluna vertebral” dos conceitos centrais sobre o cinema de Deleuze está a filosofia bergsoniana, bem localizada através de quatro "comentários a Bergson” que Deleuze distribui nos dois livros. Através deles podemos entender, com grande riqueza de detalhes, as origens dos elementos que compóem o cinema e suas relações conosco, com as outras artes e com o mundo. Esse artigo tem a pretensão de analisar os dois primeiros comentários presentes em Cinema 1: A Imagem-Movimento.

Deleuze afirma que, mesmo antes do surgimento oficial do cinema, Bergson "tinha descoberto perfeitamente a existência dos cortes móveis ou da imagem movimento" já em Matéria e Memória de 1896 (DELEUZE, 1985, p. 11). Tais cortes seriam justamente o conceito de "imagem-movimento" cunhado por Deleuze. Nesse sentido, para ele, Bergson "pressentia de modo profético o futuro ou a essência do cinema” (DELEUZE, 1985, p. 12). Para entender o porquê dessa afirmação é necessário seguir a linha de pensamento construída nesse primeiro comentário a Bergson e nos atentarmos às três teses acerca do movimento, presentes em Evolução Criadora (1907) - escrito dez anos depois de Matéria e Memória. Tais teses são:

- A impossibilidade de "reconstruir o movimento a partir de imobilidades"; (DELEUZE, 1985, p. 9)

- A diferenciação entre a "ilusão antiga" e a "ilusão moderna” acerca do movimento; (DELEUZE, 1985, p. 12)

- O "instante enquanto corte imóvel do movimento" e o "movimento enquanto corte móvel na duração”. (DELEUZE, 1985, p. 17) 
Explicaremos cada uma dessas teses e de que maneira podem conectar-se ao cinema, começando pela primeira: "a impossibilidade de reconstruir o movimento a partir de imobilidades”. Na filosofia bergsoniana, o movimento não pode ser dividido - ele se encontra na "dimensão" da temporalidade e da duração que, ao contrário do espaço, não é divisível.

Em outras palavras, o movimento seria, justamente, o que acontece no intervalo, o que não notamos ao seguirmos a tendência natural de nossa percepção, que reconstitui o movimento através de imobilidades, percebendo a "parte útil” em função de nossa ação. Nossa inteligência ${ }^{2}$ nos acostumou a pensar no movimento enquanto sucessão de imobilidades: instante $\mathrm{A}$, instante $\mathrm{B}$, e assim sucessivamente, como uma série de desenhos levemente diferentes que, quando passamos os olhos, vemos em "movimento". A tal limitação de nossa percepção, Bergson deu o nome de "ilusão cinematográfica" - injustamente, como veremos melhor mais à frente, tendo em vista o cinema ao qual Deleuze se refere, pós-montagem. No cinema pré-montagem que Bergson viu surgir no final do século XIX e começo do século XX, o movimento é reconstituído através de cortes imóveis não muito diferentes da percepção natural. Essa primeira tese é o eixo central a partir do qual as outras duas se desdobrarão.

A segunda tese (ilusão antiga x ilusão moderna) também nos fornece elementos importantes para pensar o cinema. Mas, antes, cabe perguntar: que ilusão é essa, e como as versões antiga e moderna se diferenciariam? Trata-se da ilusão de nossa percepção natural (primeira tese) em ambos os casos, porém com enfoques diferentes. Os gregos antigos baseavamse no paradigma ontológico da imobilidade, tratando o Ser como o imóvel, a forma pura das coisas. A mudança (movimento) possuía um caráter de imperfeição, degradação. Julgavam os antigos que as coisas não sustentavam a forma em sua imobilidade por serem constituídas de matéria que, enquanto tal, não sustentaria a Forma acabada. A "forma”, o inteligível, seria o momento essencial capaz de exprimir o movimento. A revolução científica nos permitiu recompor o movimento de outra maneira:

[...] mesmo se o movimento fosse recomposto, ele não era mais recomposto a partir de elementos formais transcendentes (poses), mas a partir de elementos materiais imanentes (cortes). Em vez de fazer uma análise inteligível do movimento, empreendia-se uma análise sensível (DELEUZE, 1985, p. 13).

2 Conceito bergsoniano. A inteligência é instrumento da ciência, reconhece as semelhanças entre o que existe para criar ideias gerais e facilitar a ação prática sobre o mundo. Esse conceito é tratado por Bergson ao lon go de toda a sua obra. 
Isso significa que essa segunda tese marca um passo muito importante: o movimento, mesmo sendo recomposto por imobilidades em ambos os casos, não era mais recomposto de acordo com o mesmo paradigma, a síntese inteligível dos antigos (DELEUZE, 1985, p. 12), mas a partir do paradigma da análise sensível da ciência moderna, isto é, à maneira pela qual ela estrutura sua física, sua geometria, sua astronomia... reportando o movimento a um instante qualquer e não mais a um instante privilegiado. É exatamente assim que Deleuze define o cinema: "o sistema que reproduz o movimento reportando-o ao instante qualquer" ${ }^{3}$ (DELEUZE, 1985, p. 14). Sem serventia para as ciências, o cinema ganhava espaço nas artes que, aos poucos, "mudavam o estatuto do movimento", como o balé, a mímica, a dança - "O cinema pertence inteiramente a essa concepção moderna do movimento - eis o que Bergson demonstra com eloquência” (DELEUZE, 1985, p. 16). Fica nítido que o cinema não poderia corresponder a uma filosofia antiga pois lidava com o movimento à maneira moderna. Maneira esta que, presente na arte e na ciência, exigia uma filosofia que estivesse à altura: a metafísica que Bergson se propõe a fazer quando opõe sua filosofia à de seus antecessores. É precisamente nesse sentido que a segunda tese sobre o movimento abre uma possibilidade de enxergar o cinema por outra ótica "que não seria mais o aparelho da mais velha ilusão, mas, ao contrário, o órgão da nova realidade a ser aperfeiçoado” (DELEUZE, 1985. p. 17).

A maneira pela qual isso seria possível é a que nos leva para o conceito de "imagem-movimento", que se vincula à terceira tese acerca do movimento que se faz presente em A Evolução Criadora e é descrita da seguinte forma: "não só o instante é um corte imóvel do movimento, mas o movimento é um corte móvel da duração, isto é, do Todo ou de um todo.” O movimento é uma "translação no espaço" e "exprime uma mudança na duração ou no todo" (DELEUZE, 1985, p. 17).

De maneira mais nítida: quando os objetos movem-se no espaço, existe de fato uma mudança qualitativa no todo, dado bem exemplificado em $A$ Evolução Criadora, quando Bergson nos fornece o exemplo do copo com água e açúcar: quando adicionamos o açúcar à água, o movimento de dissolução das partículas implica uma mudança qualitativa no todo, i.e, de água na qual há açúcar à água açucarada. (BERGSON apud DELEUZE, 1985, p. 18) Há, portanto, uma analogia: os cortes imóveis estariam para o movimento como o movimento (como corte móvel) estaria para a mudança qualitativa [do todo].

3 “Instante qualquer" é entendido como “o instante equidistante de um outro" (DELEUZE, 1985, p. 15). 
"Com a única diferença”, salienta Deleuze, que uns [cortes imóveis] "exprimem uma ilusão" e a outra [movimento como corte móvel], uma realidade (DELEUZE, 1985, p. 18). Bergson compreende o "todo" como sendo o Aberto que, essencialmente, dura ${ }^{4}$. A mudança incessante é parte de sua configuração e, "se fosse preciso defini-lo, nós o definiríamos pela Relação” (DELEUZE, 1985, p. 19). A Relação não compõe os objetos enquanto propriedade deles, ela pertence ao todo (que não pode ser confundido com um conjunto fechado). Novamente, Deleuze elucida:

Através do movimento no espaço, os objetos de um grupo mudam suas respectivas posições. Mas, através das relações, o todo se transforma ou muda de qualidade. Da própria duração, ou do tempo, podemos afirmar que é o todo das relações (1985, p. 19-20).

Importante salientar que não podemos confundir o todo com os "conjuntos". Conjuntos são fechados (e artificialmente fechados) ${ }^{5}$ como, por exemplo, um copo de água com açúcar. Quando as partículas do açúcar se movimentam e ficam suspensas na água isso reflete uma mudança no todo, "no conteúdo do copo, uma passagem qualitativa da água onde há açúcar ao estado de água açucarada” (DELEUZE, 1985, p. 18). Já vimos como um corte imóvel se relacionaria com o movimento ${ }^{6}$ - agora esse exemplo que Bergson nos dá em $A$ Evolução Criadora nos permite compreender de que maneira o movimento como corte móvel estaria para a mudança qualitativa.

O todo está na metafísica bergsoniana como algo "espiritual” ou "mental” porque cria-se constante e indefinidamente "numa outra dimensão sem partes". O que fazemos, portanto, ao considerarmos o exemplo do copo de água, é justamente realizar um recorte no todo. A própria organização da matéria nos permite considerar os "sistemas fechados”, e, dessa forma, podemos dizer que se tais conjuntos fechados se localizam no espaço, os “todos” estão na duração ou são eles mesmos a própria duração (DELEUZE, 1985, p. 19-20).

Com isso, Deleuze localiza um estatuto mais rigoroso e complexo: os conjuntos fechados seriam "compostos” de cortes imóveis, "cujos estados sucessivos são calculados sobre um tempo abstrato" e o todo, esse todo que é ele próprio a duração, inclui o "movimento

\footnotetext{
$4 \quad$ "Instante qualquer" é entendido como "o instante equidistante de um outro" (DELEUZE, 1985, p. 15).

$5 \quad$ Artificialmente porque esses conjuntos nunca são absolutamente fechados - eles compõem o todo que está em constante mudança e por isso nunca se isolam completamente (DELEUZE, 1985, p. 20).

6 Na impossibilidade de o "movimento ser reconstituído a partir de cortes imóveis".
} 
real” que remete à abertura desse todo e "cujos movimentos são os tantos cortes móveis que atravessam o sistema fechado" (DELEUZE, 1985, p. 20-21).

Terminando a terceira tese, Deleuze identifica três níveis. Estes seriam: 1) os "conjuntos” [sistemas fechados] que podem ser definidos através dos objetos ou de suas "partes distintas"; 2) "o movimento de translação, que se estabelece entre esses objetos e modifica suas posiçôes respectivas"; e, por fim, “3) a duração ou o todo, realidade espiritual que não para de mudar segundo suas próprias relaçóes” (DELEUZE, 1985, p. 21).

Identificados os três níveis, podemos dizer que o movimento possui duas faces. É, ao mesmo tempo, "o que se passa entre os objetos ou partes" e "o que exprime a duração ou o todo". Ou ainda,

Ele faz com que a duração, ao mudar de natureza, se divida nos objetos, e que os objetos, ao se aprofundarem, perdendo seus contornos, reúnam-se na duração. Dir-se-á então que o movimento reporta os objetos de um sistema fechado à duração aberta e a duração aos objetos do sistema que ela força a se abrirem (DELEU ZE, 1985, p. 21).

Dessa maneira, se o movimento é um "corte móvel na duração" podemos entender com mais facilidade o primeiro capítulo de Matéria e Memória e sua tese de que não existem apenas imagens instantâneas, isto é, “cortes imóveis do movimento” mas existem também “imagens-movimento" que são "cortes móveis na duração": "imagens-mudança, imagens-relação, imagens-volume, para além do próprio movimento...” (DELEUZE, 1985, p. 21).

$\mathrm{O}$ que o cinema passou a nos oferecer, já na primeira metade do século XX, é, justamente, imagem-movimento. Porém, isto deu-se apenas com a montagem, a "emancipação da filmagem” (DELEUZE, 1985, p. 11-12). No período em que Bergson escreveu suas obras o cinema estava engatinhando e, pela disponibilidade tecnológica da época, condenado a imitar a percepção natural. Quando o plano passa a ser uma categoria temporal (e não mais espacial) o corte passa a ser móvel, e o cinema finalmente pode reencontrar a imagem-movimento do primeiro capítulo de Matéria e Memória (DELEUZE, 1985).

Isso significa, mais precisamente, que o cinema, agora possuindo planos em categorias “temporais", constrói-se de imagens-movimento - os cortes móveis na duração. Deleuze parte dos conceitos bergsonianos para estruturar a construção de conceitos a respeito do cinema, contudo, para o leitor que não possui familiaridade com a obra de Bergson, a riqueza des se vínculo pode passar despercebida. Explicitar tal ponte faz-se necessário enquanto ambição filosófica. 


\section{A IMAGEM-MOVIMENTO E SUAS TRESS VARIEDADES - O SEGUNDO COMENTÁRIO A BERGSON REALIZADO POR DELEUZE.}

No início de seu segundo comentário a Bergson, Deleuze coloca a crise filosófica com a qual Bergson lidou. "O que parecia sem saída, afinal, era o confronto do materialismo com o idealismo, um querendo reconstituir a ordem da consciência com puros movimentos materiais, o outro, a ordem do universo com puras imagens na consciência” (DELEUZE, 1985, p. 76).

Matéria e Memória busca uma resolução para essa questão e seu primeiro capítulo é de fundamental importância para a construção dos conceitos que aparecem em Cinema 1, de Deleuze. Antes do surgimento oficial do cinema, Bergson “já tinha descoberto" a existência das imagens-movimento, ou cortes móveis, (DELEUZE, 1985, p. 11) também oferecidos a nós pelo cinema que Bergson não viveu para assistir. Uma vez que, com a montagem, os planos do cinema deixaram de corresponder a uma categoria espacial e tornaram-se temporais há, como apontado por Deleuze, um "reencontro" dele com a "imagem-movimento” desse capítulo inicial de Matéria e Memória (DELEUZE, 1985, p. 12)

A frase introdutória do primeiro capítulo de Matéria e Memória, livro citado por Deleuze durante todo o segundo comentário, é uma declaração desse ímpeto de defender o conceito de "imagem” para além da dicotomia espírito/matéria. O que Bergson sugere nas primeiras páginas é justamente um "fingimento" que serve de exercício: Se suspendermos por ora "as teorias da matéria e do espírito", o que restaria? Estaríamos na presença de coisas de qual natureza? Bergson utiliza o termo 'imagem' para se referir ao universo das coisas materiais (o mundo e nossos próprios corpos) sem isolá-lo completamente de sua dimensão metafísica (BERGSON, 1999, p. 11).

Neste sentido, o que observamos são tais imagens agindo e reagindo umas sobre as outras "segundo leis constantes, que chamo leis da natureza" (BERGSON, 1999). Essa é a chave argumentativa que Bergson utiliza na intenção de superar a dicotomia idealismo/materialismo: se tudo o que ocorre no Universo fosse regido exclusivamente por tais leis da natureza, uma ciência perfeita seria capaz de "calcular e prever o que se passará em cada uma dessas imagens, o futuro das imagens deve estar contido em seu presente e a elas nada acrescentar de novo" (BERGSON, 1999). A constatação de que os seres vivos não estão submetidos completamente às leis da natureza, por poderem escolher de alguma forma a maneira pela qual "devol- 
vem” os movimentos que recebem de outras imagens, constitui, para Bergson nesta obra, o fundamento do que será explorado rumo à superação de tal dualismo.

É importante ressaltar que na perspectiva bergsoniana o tecido da realidade é composto de mistos que separam-se apenas de forma "abstrata", na leitura de mundo que a inteligência nos possibilita. Dessa forma, o método próprio do bergsonismo, a intuição, constitui-se como método porque, além do fato de possuir um processo bem definido (descrito por Deleuze no primeiro capítulo de Bergsonismo) visa a compreensão da Duração com precisão (de forma tal que seria impossível fazê-lo sem um método filosófico rigoroso) de maneira análoga à habilidade da inteligência de conhecer com precisão a materialidade através do método científico.

A grande dificuldade da prática filosófica para Bergson, nesse sentido, é a de utilizar a inteligência em sua própria violência, tal qual seu método propóe. Em outras palavras, Bergson insiste que, uma vez que somos mistos de matéria e memória, um corpo que também é consciência, é de primeira necessidade entender o que constitui cada domínio.

Nossa consciência, metafísica, imaterial, é o terreno da filosofia que, no método intuitivo bergsoniano, possui como primeiro ato a reformulação dos problemas tendo em vista as nervuras dessa realidade que sofre variações de grau no que concerne à matéria, ao espaço, à homogeneidade desse terreno e às variaçóes de natureza no que diz respeito à natureza da própria duração.

Exemplos das consequências dessa confusão podem ser constatados ao analisarmos Bergson discorrer acerca dos pseudoproblemas do nada, do possível e da desordem. Tal argumentação encontra-se presente no artigo "O possível e o real”, publicado em uma outra edição de O Pensamento e o Movente (BERGSON, 2006) além da qual citamos até agora, de 1974.

O segundo ato consistiria em identificar as diferenças de natureza para que em um terceiro momento recuperemos o tempo real, a própria duração que não deve ser confundida, como tantas vezes ressaltado por Bergson, com o tempo espacializado, quarta dimensão do espaço (DELEUZE, 2012, p. 10).

Em Bergsonismo, Deleuze explicita a intuição como método filosófico através de cinco regras. Isto é fundamental para compreender qual a chave de leitura que Deleuze utiliza para se referir à duração. "A intuição, tal como ele [Bergson] a entende metodicamente, já supõe a duração”. (DELEUZE, 2012, p. 9). A terceira regra é clara: 
Isso porque, na construção bergsoniana, o espaço refere-se a uma construção intelectual, referindo-se à matéria e suas variações de grau. É a duração que, no terreno da memória, do intangível, refere-se às diferenças de natureza entre as coisas. Isso é fundamental para a filosofia do cinema pois as "imagens-movimento" referem-se, justamente, aos blocos de duração, a recortes de um todo. Como nos referimos na primeira seção desse trabalho, na terceira tese sobre o movimento, referente ao primeiro comentário a Bergson: "o movimento en quanto corte móvel na duração”.

Há entre os paradigmas materialista e idealista uma diferença ontológica da concepção do que seria a consciência. Não podemos definir a filosofia bergsoniana em nenhum dos dois paradigmas. Para Bergson, "toda consciência é alguma coisa”. Sua metafísica pressupõe a existência tanto de uma dimensão material, corpórea, quanto de uma dimensão imaterial, da consciência; que constituem o Absoluto. Essa é a tese fundamental de Matéria e Memória.

É necessário insistir no ponto que Bergson privilegia a todo tempo: a realidade imaterial não é menos real que a matéria que encontra-se em movimento, a extensão. Essa realidade imaterial é a própria consciência, vivida, experimentada, que apesar de ser possibilitada pelo cérebro não é localizada no cérebro, não possui extensão de maneira alguma. É apenas nesse sentido do tempo da consciência que é possível falar em “tempo real para Bergson”.

Parece natural, assumindo tais premissas, que a conclusão é a possibilidade de separarmos em nossa análise (segundo o método intuitivo) os elementos que são próprios da análise dessa realidade em seu aspecto material (diferenças de grau) e os elementos que são próprios da realidade em seu aspecto "psíquico" (diferenças de natureza).

Se Bergson denuncia o cinema como “aliado ambíguo”, como afirma Deleuze, é pelas mesmas razóes que a percepção natural: ambos captam o movimento a partir de imobilidades. E a percepção natural, por essa razão, “não possui privilégio algum” (DELEUZE, 1985, p. 78)

Importante salientar mais uma vez que a referência que Bergson faz ao cinema relaciona-se ao cinema pré-montagem, o que, como veremos, faz toda a diferença na concepção de movimento presente nele e no reencontro póstumo sugerido por Deleuze entre a metafísi- 
ca bergsoniana e o cinema pós-montagem, que encontra o plano temporal. Em outro trecho do Segundo comentário, Deleuze diz:

[...] para Bergson, o modelo não pode ser a percepção natural, que não possui privilégio algum. O modelo seria antes um estado de coisas que não pararia de mudar, uma matéria fluente onde nenhum ponto de ancoragem ou centro de referência seriam imputáveis. A partir desse estado de coisas, seria necessário mostrar como podem se formar centros em pontos quaisquer, que imporiam vistas fixas instantâneas. Tratar-se-ia, portanto, de "deduzir" a percepção consciente, natural ou cinematográfica [...] Mesmo através de sua crítica do cinema, Bergson estaria no mesmo plano que ele, e muito mais ainda do que imaginava. É o que vamos ver com o deslumbrante primeiro capítulo de Matéria e Memória. (DELEUZE, 1985, p. 78)

A mesma imagem que vem sendo reivindicada enquanto matéria aqui também é reivindicada por Deleuze enquanto movimento pois, em suma, trata-se da mesma coisa: matéria é matéria em movimento, portanto, imagem-movimento. A afirmação resgatada de Matéria e Memória, a saber, "Cada imagem age e reage sobre as outras em 'todas as suas faces' e 'através de todas as suas partes elementares” (BERGSON apud DELEUZE, 1985, p. 78-79) refere-se justamente a esse movimento: a interpenetração contínua da matéria em si mesma na duração e, portanto, no tempo real.

Este conjunto infinito de todas as imagens constitui uma espécie de plano de imanência. Neste plano a imagem existe em si. Este em-si da imagem é a matéria: não algo que estaria escondido atrás da imagem, mas ao contrário, a identidade absoluta da imagem e do movimento. [...] A imagem-movimento e a matéria fluente são estritamente a mesma coisa. (DELEUZE, 1985, p. 78, grifo nosso).

A maneira pela qual essa imagem-movimento relaciona-se com os centros de indeterminação que são os seres vivos explica-se nos conceitos de percepção, ação e afecção em Matéria e Memória e seus correlatos na filosofia do cinema: imagem-percepção, imagem-ação e imagem-afeç̧ão (além da própria imagem-movimento, quando tal imagem não se relaciona a centro de indeterminação algum).

De forma mais nítida: A imagem-movimento é geradora de suas variaçôes citadas acima. O leitor que se dirigir ao primeiro capítulo de Matéria e Memória encontrará a lei já mencionada anteriormente de que percepção dispóe do espaço na exata medida em que a ação dispõe do tempo: bem, na imagem privilegiada que são nossos corpos, nossos sentidos se abrem para perceber os aspectos da realidade com os quais podemos interagir. Em outras pala- 
vras, quanto mais coisas um ser vivo é capaz de perceber [no espaço] maior o hiato [tempo] de resposta de sua ação.

Analisemos o comportamento de um ser rudimentar, como uma ameba. Sua percep̧̧ão limitada apenas permite que tal animal sinta o contato do toque diretamente, que a faz reagir $[a c ̧ \tilde{a} o]$ imediatamente. Nós, seres humanos, subtraímos da realidade ${ }^{7}$, ou seja, percebemos, uma grande gama de coisas através de nossos cinco sentidos que usamos para construir uma representação de mundo (daí o nome do primeiro capítulo ao qual estamos nos referindo: "Da seleção das imagens para a representação: O papel do corpo") e, consequentemente, nosso tempo de resposta para uma possível ação é infinitamente maior.

Há, entre a percepção e a afecção, uma diferença de natureza. Se a percepção é uma subtração do que é útil a mim da realidade material em minha volta, ou seja, o que apreendo com meu corpo dos objetos que me circundam, a afeç̧ão é a percepção que se faz no contato direto com meu corpo e que, assim, eu sinto no meu corpo: a imagem privilegiada que é o meu ser. A totalidade das imagens continua existindo mesmo se nosso corpo desaparece, ao passo que não podemos excluir nosso corpo sem fazer desaparecer nossas sensaçôes [afecçôes]. Portanto entre as duas, há uma diferença de natureza. (BERGSON, 1999, p. 59)

Vamos nos ater agora às variações da imagem-movimento, presentes no segundo comentário:

\footnotetext{
Veremos que tais imagens [imagem-movimento] se formam efetivamente no universo (imagens-ação, imagens-afecção, imagens-percepção). Mas elas dependem de novas condiçôes, e evidentemente não podem aparecer por enquanto. Por enquanto só dispomos de movimentos, chamados imagens. (DELEUZE, 1985, p. 80)
}

A diferenciação aprofundada aqui por Deleuze refere-se à distinção entre matéria inerte e a matéria capaz de possuir percepção, ação e afecção: os corpos; que tratam-se de imagens privilegiadas, uma vez que podem escolher a maneira pela qual devolvem o movimento que recebem de outras imagens (ação), percebem-se de dentro (afecção) e percebem essas outras imagens em sua face útil (percepção).

Se Deleuze se apropria construtivamente de conceitos bergsonianos referentes à nossa condição enquanto seres vivos em relação às imagens que nos rodeiam é porque, em algum grau, está olhando para o cinema de forma semelhante, ou seja, enquanto sistemas de

$7 \quad$ O conceito bergsoniano de percepção refere-se à uma "subtração" da realidade que nossos corpos apreendem. 
imagens que alteram-se qualitativamente entre si. Nesse sentido, o advento da montagem é absolutamente fundamental pois é nela que o cinema explora a "mobilidade de seus centros, a variabilidade de seus enquadramentos” (DELEUZE, 1985, p. 86).

Na última página de seu "segundo comentário a Bergson” Deleuze conclui: O plano de conjunto, ou seja, o enquadramento de um cenário no qual um ou mais personagens podem ser vistos com facilidade seria, sobretudo "uma imagem-percepção", "o plano médio", no qual a câmera está a uma distância média do objeto, "uma imagem-ação", e "o primeiro plano", a imagem em close, “uma imagem-afecção” (DELEUZE, 1985, p. 94).

Para fins de conclusão do que está sendo exposto no presente trabalho, analisaremos a seguinte citação de La Salvia que cremos sintetizar bem a análise deleuziana do cinema:

O cinema, ao longo do desenvolvimento de sua especificidade, demonstrou que não pretendia recompor o movimento a partir de instantes fixos como cortes imóveis, mas que considera suas imagens como imagens médias que são tomadas em um fluxo contínuo e mais, garantido pela montagem e pelos movimentos da câmera, cria uma mudança qualitativa a partir de cortes móveis (LA SALVIA, 2012, p. 35).

Tal citação mobiliza bem o argumento deleuziano defendido aqui: o cinema pósmontagem reencontrou a imagem-movimento presente na metafísica bergsoniana com louvor, justamente, "criando uma mudança qualitativa a partir de cortes móveis”. Esse é um grande feito dada a "evolução" indicada por Deleuze em Bergsonismo do conceito de duração, "executada” pelo cinema através de blocos de duração. Isto porque "a duração pareceu-lhe cada vez menos redutível a uma experiência psicológica, tornando-se a essência variável das coisas e fornecendo o tema de uma ontologia complexa” (DELEUZE, 2012, p. 28).

Entendemos que não é possível tratar da abrangência necessária que essas obras emanam em um trabalho desse porte. É necessária uma longa abordagem desse tema, como as produçốes de Machado e de La Salvia a respeito dessa temática, por exemplo. O que pretendemos aqui, é contribuir para puxar o fio, como outros autores fizeram, da ponte entre esses complexos e fundamentais autores franceses. Em suma, podemos resumir a intenção desse artigo em dizer, como La Salvia coloca, que

O estudo de Bergson permite entender como a montagem é, por um lado, operadora de cortes móveis de mudanças qualitativas [...] e, por outro lado, usa o modelo da percepção natural para dar sentido às imagens segundo um esquema que o espectador identifique o que se passa e não perca o movimento (Segundo Comentário) (LA SALVIA, 2012, p. 38) 
O Cinema em Gilles Deleuze: apontamentos sobre a imagem-movimento

É importante ressaltar que nos atentamos aqui apenas aos primeiros comentários realizados a Bergson. Existem outras variaçốes das imagens-movimento trabalhadas em Cinema 2: A Imagem-tempo que não foi nossa intenção abordar aqui, dada a natureza de um artigo. Contudo, seria de grande valor construir um comentário com mais abrangência da obra deleuziana voltada à sétima arte em uma pesquisa de porte maior. 


\section{REFERÊNCIAS BIBLIOGRÁFICAS}

BERGSON, H. Cartas, conferências e outros escritos. Tradução de Franklin Leopoldo e Silva, $1^{\circ}$ edição. São Paulo: Editora Abril Cultural, 1974. (Coleção Os pensadores)

BERGSON, H. Matéria e Memória. 2 ed. São Paulo: Martins Fontes, 1999.

BERGSON, H A Evolução Criadora. São Paulo: Martins Fontes, 2005.

BERGSON, H. O Pensamento e o Movente. São Paulo: Martins Fontes, 2006.

DELEUZE, G. Cinema 1: A Imagem-Movimento. São Paulo: Editora Brasiliense, 1985.

DELEUZE, G. Cinema 2: A Imagem-Tempo. São Paulo: Editora Brasiliense, 2005.

DELEUZE, G. Bergsonismo. São Paulo: Editora 34, 2012.

LA SALVIA, A. L. As relaçôes entre imagens: um estudo dos conceitos do Cinema para Gilles Deleuze. Editora Livros Ilimitados, 2012.

MACHADO, R. Deleuze, a arte e a filosofia. Editora Zahar, Rio de Janeiro, 2009. 